Esta revista forma parte del acervo de la Biblioteca Jurídica Virtual del Instituto de Investigaciones Jurídicas de la UNAM www.juridicas.unam.mx

http://biblio.juridicas.unam.mx

\title{
LÉON DUGUIT EN BUENOS AIRES: SOCIABILIDAD Y POLÍTICA EN LA RECEPCIÓN DE UNA TEORÍA JURÍDICA
}

\author{
SOCIABILITY AND POLITICS IN THE RECEPTION \\ OF LEON DUGUIT'S LEGAL THEORY: THE ARGENTINE CASE
}

\author{
Carlos Miguel HERRERA*
}

\begin{abstract}
Resumen:
Este trabajo estudia la visita que realizará el jurista francés Léon Duguit en Argentina, a mediados de 1911. Su viaje puede ser considerado como un ejemplo de los intercambios que se producen entre Francia y América a principios del siglo XX. El carácter original de la concepción jurídica de Duguit, en particular su acento social, tendrá consecuencias importantes en las reacciones que produce la exposición de sus ideas y en la construcción de la recepción de las mismas. Estas son representativas de las transformaciones que están viviendo las disciplinas jurídicas en ese momento.
\end{abstract}

Palabras clave:

Léon Duguit, ciencia jurídica, circulación, recepción, Argentina.

* Catedrático y director del Centre de Philosophie Juridique et Politique de la Universidad de Cergy-Pontoise, carlos.herrera@u-cergy.fr 
Esta revista forma parte del acervo de la Biblioteca Jurídica Virtual del Instituto de Investigaciones Jurídicas de la UNAM

Abstract:

This article discusses Leon Duguit's 1911 visit to Argentina. This visit can be considered as exemplary regarding cultural exchanges in legal theory between France and America in the early twentieth century. Duguit's interesting legal conception, in particular the social aspect of his theory will have important consequences in legal thought in Argentina. Consequences that I consider can be seen nowadays regarding the undergoing transformation of legal thought in our western legal tradition.

\section{Keywords:}

Léon Duguit, Legal Science, Circulation, Reception, Argentina. 
Esta revista forma parte del acervo de la Biblioteca Jurídica Virtual del Instituto de Investigaciones Jurídicas de la UNAM www.juridicas.unam.mx

http://biblio.juridicas.unam.mx

SOCIABILIDAD Y POLÍTICA EN LA RECEPCIÓN DE UNA TEORÍA

Si el problema de la circulación de conceptos se ha tornado una problemática central de los estudios jurídicos comparados desde hace varias décadas, conviene siempre insistir que la cuestión no puede reducirse a un mero análisis en términos de "influencia", toda vez que las condiciones materiales de recepción deben ser tomadas muy especialmente en cuenta para reconstruir un proceso intelectual complejo que dista de ser puramente "espiritual". Y más aún cuando, a partir de fines del siglo XIX, el avance de las comunicaciones y de los medios de transporte permitieron el desplazamiento de los propios autores con sus teorias a cuestas, aportando en su equipaje códigos de lectura, y eventualmente, si la teoria era ya difundida entre sus receptores locales, sus juicios sobre réprobos y elegidos. ${ }^{1}$

En ese contexto, la Facultad de Derecho, y la Universidad de Buenos Aires toda, aparecía, pese a las distancias geográficas, como el principal centro intelectual de la América hispana, convirtiéndose en un destino habitual para intelectuales y universitarios europeos, con predominancia de autores españoles y franceses en las primeras décadas del siglo XX.

Este trabajo se propone analizar el viaje que el jurista francés Léon Duguit (1859-1928) realizará a la Argentina, invitado por la Facultad de Derecho de Buenos Aires, para

\footnotetext{
1 Un caso notable en ese sentido es el de la recepción de la teoría de Hans Kelsen en Argentina. Véase Sarlo, Oscar, "La gira suramericana de Hans Kelsen en 1949: el 'frente del sur' de la teoría pura”, en Ramírez Cleves, Gonzalo (ed.), Ecos de Kelsen, Bogotá, Universidad Externado de Colombia, 2013. Sin duda, en lo que se refiere a conceptos teóricos, o más precisamente, a teorías del derecho, las modalidades de transferencia encierran también algunos trazos específicos, en la medida que dichas construcciones tienen vocación a circular de manera más "universal" que las elaboraciones de las doctrinas jurídicas "nacionales". Cfr. López Medina, Diego, Teoría impura del derecho. La transformación de la cultura jurídica latinoamericana, Bogotá, Legis, 2004, pp. 11-12.
} 
Esta revista forma parte del acervo de la Biblioteca Jurídica Virtual del Instituto de Investigaciones Jurídicas de la UNAM www.juridicas.unam.mx

http://biblio.juridicas.unam.mx

\section{CARLOS MIGUEL HERRERA}

impartir lecciones universitarias en septiembre de $1911 .^{2} \mathrm{E} 1$ catedrático que llegaba a la ciudad porteña en la fuerza de la edad venía precedido ya de amplia fama; Duguit era considerado por entonces como uno de los mayores exponentes del derecho público francés. Si el inicio de su carrera había sido fulgurante - accede a la cátedra con apenas 23 años, adjudicándose una plaza en su primer concurso de agrégation-, su obra propiamente dicha había comenzado en 1901, con la publicación, en sendos volúmenes sucesivos, de dos estudios sobre el Estado. ${ }^{3}$ Poco después, en una de esas formas de consagración típicas de la profesión jurídica, Duguit editaba un Manual de derecho constitucional, que en momentos en que llega a las costas del Plata se había transformado ya en Tratado, siendo como tal ampliado y reeditado dos veces hasta su muerte.

No era, con todo, el único rasgo del visitante que podía destacarse: su conceptualización jurídica, e incluso su actuación pública, se inscribía en un universo republicano, laico y social. Lanzado desde unos años antes a la política municipal de su ciudad Burdeos, venía desarrollando en sus trabajos jurídicos una visión muy precisa de la evolución social, que podía ordenarse en torno a un ideal de solidaridad social, en una perspectiva de conciliación "objetiva" de intereses, pero que lo llevaba, ya en otro orden de cosas, a promover la renovación de los mecanismos representativos de la democracia parlamentaria.

En las páginas que siguen nos detendremos en algunos aspectos de la estadía del jurista francés, como sus ecos en la prensa nacional o su red de sociabilidades, en la medida que son ya indicativos del interés político e intelectual que podía generar su concepción. Estudiaremos luego el discurso que despliega Duguit ante sus interlocutores, buscando

2 El proyecto de hacer público los archivos conservados por la familia de Léon Duguit no ha sido aún concretado. Ignoro por ende si existen testimonios específicos con respecto a su viaje a Buenos Aires.

3 L'Etat, le droit objectif et la loi positive, París, Fontemoing, $1901 \mathrm{y}$ L'Etat les gouvernants, et les agents, París, Fontemoing, 1903. 
Esta revista forma parte del acervo de la Biblioteca Jurídica Virtual del Instituto de Investigaciones Jurídicas de la UNAM www.juridicas.unam.mx

http://biblio.juridicas.unam.mx

SOCIABILIDAD Y POLÍTICA EN LA RECEPCIÓN DE UNA TEORÍA

determinar las condiciones de recepción que podía hallar su teoría entre los juristas argentinos de la época.

I

Contrariamente a lo que se podía pensar, habida cuenta del peso de la cultura francesa en la élite argentina de aquel entonces, Léon Duguit era el primer profesor galo que dictaba cátedra en la Facultad de Derecho de Buenos Aires. El futuro decano de Burdeos se transformaría en el jurista francés de su generación que más viaja al extranjero: New York, Madrid, Lisboa, Coimbra, Bucarest, El Cairo serán algunos de sus destinos, incluyo ya avanzado en edad. Pero pareciera que es la visita a Buenos Aires que despierta una vocación viajera que se consolidará después de la Primera guerra mundial —en su primera conferencia Duguit asegura que la invitación de la Universidad de Buenos Aires "será el gran honor de mi vida de profesor"-. Por cierto, no era el primer jurista extranjero que disertaba en la Facultad de Derecho en esos años; ya lo habían precedido en la cátedra el español Rafael Altamira, en 1909, o el italiano Enrico Ferri, en 1910.

Pero, a diferencia de aquellos, la invitación a Duguit parece haber surgido exclusivamente de la Facultad, y, de hecho, el profesor francés sólo se limita a una corta estadía de tres semanas. Según la crónica periodística, es al muy activo profesor de filosofia del derecho Antonio Dellepiane (1864-1939) a quien se debe la iniciativa del convite, aunque no pareciera estar presente en momentos en que se concreta la visita. ${ }^{4}$ Dellepiane era presentado por la prensa

4 El encuentro se habría producido en París según la prensa, tal vez en ocasión de las conferencias que Duguit dictara en 1908 en la École des Hautes Études en Sciences Sociales, y que son conocidas en la Argentina. Dellepiane estaba, por otro lado, en contacto con Adolfo Posada, uno de los difusores de las ideas de Duguit en España. Posteriormente, uno de sus libros será traducido al francés en la célebre "Biblioteca de sociología", Les sciences et la méthode reconstructive, París, Giard et Brière, 
Esta revista forma parte del acervo de la Biblioteca Jurídica Virtual del Instituto de Investigaciones Jurídicas de la UNAM www.juridicas.unam.mx

http://biblio.juridicas.unam.mx

\section{CARLOS MIGUEL HERRERA}

como uno de los "discípulos preferidos" de Duguit, lo que por cierto, no tenía mayor asidero, aunque está claro que le ha facilitado un conjunto de informaciones sobre la Argentina, empezando por las referencias al Código civil y su autor Dalmacio Vélez Sarsfield. Especialista en criminología, sin duda la vía social del derecho por entonces, Dellepiane se mostraba particularmente abierto hacia la sociología, cuya cátedra ocupará más tarde. En un discurso ante los nuevos graduados de Derecho pronunciado dos años antes de la llegada de Duguit, Dellepiane había subrayado la urgencia en la exploración de las cuestiones sociales por parte de las ciencias sociales, de cara a su solución.

Duguit no era tampoco la única figura francesa que se dirigía al público porteño en ese tiempo; un conjunto de significativas personalidades se venían sucediendo: Anatole France en 1909, Georges Clemenceau al año siguiente. Unas semanas antes de la llegada del jurista de Burdeos, Victor Margueritte (1866-1942), escritor exitoso por entonces, había comenzado a dar una serie de conferencias en el Teatro del Odeón, el mismo escenario que habia visto tiempo antes a sus célebres compatriotas. Sin olvidar que 48 horas antes de la partida de Duguit, hace su llegada a Buenos Aires Jean Jaurès, cuyo viaje tendrá importantes ecos en la vida pública argentina. 5 Se trataba, en estos casos, de figuras públicas que eran contratados por un empresario privado para dictar un conjunto de conferencias (incluso el primer viaje de Ferri, en 1908, obedece a esta lógica comercial). A principios de septiembre de 1911, iniciaba un curso de literatura comparada Ernest Martinenche (1869-1939), cuyo programa, siempre en francés, era anunciado detalladamente por los periódicos de la época. ${ }^{6}$ Empero, el más es-

1915. Dellepiane es igualmente el hermano del por entonces jefe de la policía, lo que dará lugar a algunos comentarios jocosos en la prensa.

5 Para más detalle, véase Herrera, Carlos Miguel, “Jaurès en la Argentina - La Argentina de Jaurès”, Estudios Sociales, núm. 37, 2009.

6 Martinenche, profesor a la Sorbonne, es titular de la cátedra de literaturas hispánicas y al mismo tiempo un activo gestor de las relaciones 
Esta revista forma parte del acervo de la Biblioteca Jurídica Virtual del Instituto de Investigaciones Jurídicas de la UNAM www.juridicas.unam.mx

http://biblio.juridicas.unam.mx

SOCIABILIDAD Y POLÍTICA EN LA RECEPCIÓN DE UNA TEORÍA

perado de los universitarios franceses en esas semanas es, a juzgar por la prensa, el médico Fernand Widal (18621929), catedrático de patología interna de la Universidad de París, inventor del método para diagnosticar la fiebre tifoidea, cuyas fotografias en el parisino Hospital Cochin ilustran la crónica ya antes de su llegada. En ese mes de septiembre de 1911, bajo la rúbrica "Los conferencistas franceses", los diarios anuncian no menos de 5 intervenciones, desde el médico al jurista, del político a la poetisa. ${ }^{7}$

El arribo de Duguit parece haber pasado algo desapercibido para los periódicos, ${ }^{8}$ pero, ya alojado en uno de los principales hoteles del centro de Buenos Aires (el Grand Hotel ubicado en la esquina de las calles Florida y Rivadavia), la prensa se interesa pronto por la personalidad de este jurista "cuyo apellido es mejor conocido que pronunciado". Ciertamente, no sin errores: el diario La Prensa lo califica así de "eminente civilista" y "profesor de la Sorbonne"... E1 otro gran periódico nacional, La Nación, algo más preciso, lo presenta como una "personalidad descollante de las ciencias jurídico-sociales". Quizás resulte más llamativo que se considere su personalidad, como hace el cronista de $L a R a-$ zón, otro de los diarios de gran tirada del Buenos Aires de entonces, "ligada espiritualmente con el punto de vista argentino". Como sea, el periodista anota tras su encuentro,

universitarias entre Francia y América Latina - era el secretario general del Groupement des Universités et Grandes écoles de France pour les relations avec l'Amérique Latine- lo que explica que su círculo de relaciones universitarias sea más extendido que el de Duguit, en un país que ya ha visitado un año antes. Hará incluso un tercer viaje en 1922 (cfr. Delpy, Gaspard, "Ernest Martinenche", Bulletin Hispanique, 1942).

7 En efecto, a los ya citados, se debe agregar, en igual coincidencia de tiempo y lugar, el nombre de Jane Catulle-Mendès (1867-1955), cuyos ribetes mundanos aseguran a la visita una abundante cobertura periodistica.

$8 \mathrm{Su}$ llegada se habría producido el 19 de agosto, según su propio testimonio, pero los diarios, salvo error, no lo anuncian ni ese día ni el 20. Hay constancia, en cambio, que ya está instalado en Buenos Aires el día 21. 
Esta revista forma parte del acervo de la Biblioteca Jurídica Virtual del Instituto de Investigaciones Jurídicas de la UNAM www.juridicas.unam.mx

http://biblio.juridicas.unam.mx

CARLOS MIGUEL HERRERA

su "gesto persuasivo, palabra fácil y un 'entrain' de convicciones en todo aquello que brota de su especulación mental". Elogia, además, su estilo "siempre bello y fácil", que hace que la mente del escritor se eleve, como escribe, sobre la filosofía del derecho. Y concluye, luego de haberlo oído hablar sobre la importancia de los intercambios intelectuales, que su obra es una "labor sana de luminosas percepciones, altamente positiva y en extremo educadora". ${ }^{9}$

En vísperas de su primera conferencia, Duguit prefiere puntualizar que sus intervenciones serán "eminentemente universitarias, para quitarles de este modo el carácter de teatralidad". ${ }^{10}$ En cada entrevista insistirá fuertemente en este tópico, y la crónica periodística dejará constancia que el orador se propone dictar su cátedra con "la más absoluta sencillez, exenta de toda tendencia a oratoria efectista".11 Duguit parece así querer tomar distancia de los conferencistas que circulaban por Buenos Aires, con un rechazo explícito por la vulgarización, en momentos que uno de los profesores de la Facultad de Derecho, Leopoldo Maupas, desmerecía en las páginas de los Anales de la Facultad de Derecho la oralidad en beneficio del escrito en el trabajo científico. ${ }^{12}$ Duguit declaraba, además, su intención de rehuir en lo posible las abstracciones propias de la materia constitucional. Al presentar el tema general de sus conferencias ante la prensa, subrayaba sin embargo que se estaba viviendo "uno de los períodos más fecundos y rebosantes de interés en la historia de los principios constitucionales que han regido la gobernación de los pueblos", destacando de antemano que le interesaba estudiar las transformaciones de la voluntad, del contrato y la propiedad. Especialista de derecho constitucional y administrativo, en una Universidad, como la francesa, que separa cada vez más en el pla-

9 La Razón, 25 de agosto de 1911.

10 La Prensa, 22 de agosto de 1911.

11 El Diario, 23 de agosto de 1911.

12 El italiano Enrico Ferri había sido muy criticado por ello en la ocasión de su primera visita a Argentina, en 1908. 
Esta revista forma parte del acervo de la Biblioteca Jurídica Virtual del Instituto de Investigaciones Jurídicas de la UNAM www.juridicas.unam.mx

http://biblio.juridicas.unam.mx

SOCIABILIDAD Y POLÍTICA EN LA RECEPCIÓN DE UNA TEORÍA

no académico el derecho privado del derecho público, los temas de su conferencia dan cuenta de su ambición teórica, al extender sus ideas al campo de la civilística, aunque las celebraciones del centenario del viejo Código Napoleón habian sido marcadas por las críticas doctrinales a la "escuela" de la exégesis. ${ }^{13}$

Pero Duguit no sólo buscaba escapar a la divulgación sino también a la propaganda, es decir de toda lectura politica de sus palabras. Ante el cronista de La Razón subrayaba que no se adscribía a ninguna secta y que se abstendría de abordar toda cuestión dogmática, destacando, una vez más, que sus intervenciones serían "exclusivamente de orden jurídico y universitario", sin incluir "ninguna cuestión política o algunos de los aspectos sociales del momento", palabras que repetirá en la introducción a su primera alocución. Esta insistencia se asiente tal vez en otras razones que el positivismo científico que reivindicaba Duguit en el plano metodológico, acaso lo suficientemente poderosas para que el decano de la Facultad de Derecho de Buenos Aires, Eduardo L. Bidau, al presentarlo a su auditorio durante su primera lección, haga referencia a una "injusta acusación de propaganda tendenciosa".

La primera conferencia de Duguit tendrá lugar el sábado 26 de agosto, a las 5 de la tarde. ${ }^{14} \mathrm{~A}$ ella asiste el ministro de Justicia e Instrucción Pública, Juan M. Garro, además del rector de la Universidad de Buenos Aires, Eufemio Uballes. Los profesores, titulares y suplentes, de la Facultad se harán presentes en gran número y la crónica periodística

13 Sobre, el tema, véase Herrera, Carlos Miguel, "Renovación y crítica del derecho en Francia durante la Tercera República”, en García Villegas, Mauricio y Saffon, María Paula (eds.), Crítica jurídica comparada, Bogotá, Universidad Nacional de Colombia, 2011.

14 Tal como las reconstruyo por la prensa, las otras conferencias se desarrollarían el martes 29 de agosto, el sábado 2 de septiembre, el miércoles 6 de septiembre, el sábado 9 de septiembre, y la última, ya en la víspera de su partida, el miércoles 13 del mismo mes. Las fechas habian sido fijadas definitivamente una vez que el visitante se hallase instalado en Buenos Aires pero Duguit no parece haberse salido del programa original. 
Esta revista forma parte del acervo de la Biblioteca Jurídica Virtual del Instituto de Investigaciones Jurídicas de la UNAM www.juridicas.unam.mx

http://biblio.juridicas.unam.mx

CARLOS MIGUEL HERRERA

señala entre otros a Juan Agustín García, Ernesto Quesada, Alejandro Ruzo, J. A. Figueroa, Alfredo L. Palacios, Juan José Díaz Arana, A. Beccar Varela, Carlos F. Melo, Raimundo Wilmart, Adolfo Orma, Norberto Piñero, Mario Carranza, Rafael Herrera Vegas, Tomás R. Cullen, David de Tezano Pintos, muchos de ellos muy preocupados por la cuestión social. Según la tradición, se pondrán de pie y aplaudirán cuando Duguit entre a la sala de grados de la vieja Facultad de la calle Moreno, acompañado del decano.

Al presentarlo al claustro, Bidau subrayará el hecho que Duguit era el primer profesor francés que dictaba cátedra en la Facultad de Derecho. Y, tras recordar la dependencia del pensamiento argentino con esa fuente gala, lo ubicaba en la corriente de los grandes educadores franceses que habían actuado en la Argentina desde el siglo XIX. En particular, como vimos, recalcaba su carácter de hombre de ciencia, aunque se tratase de un pensador con "vistas originales sobre la transformación futura de la sociedad civilizada contemporánea y de algunos principios en que se asientan el derecho público y el privado". ${ }^{15} \mathrm{El}$ tono está dado: aviso sobre sus ideas avanzadas, aunque acentuando su carácter científico y no político. Como si se tratase de despejar las consecuencias que podia tener en el medio nacional la caracterización como "sindicalista" por la que se estaba conociendo la teoría de Duguit, un sindicalismo que tenía una significación muy diferente en ambos países. ${ }^{16}$ No por nada el diario socialista La Vanguardia advertía que la

15 Bidau, Eduardo L., "Palabras pronunciadas por el decano de la Facultad, doctor Eduardo L. Bidau, al presentar al profesor Duguit", Anales de la Facultad de Derecho y Ciencias Sociales, 1911, t. I., pp. 609-610.

16 Asociada a una de las corrientes antiparlamentarias y combativas del movimiento obrero, la apelación había sufrido en Francia algunas transformaciones, que permitía ser adoptada por sectores burgueses a fines de los años 1910. Luego de sus conferencias, Duguit aparece clasificado por uno de sus interlocutores, Enrique Ruiz Guiñazú, como un sindicalista "conservador", al negar la lucha de clases, Cfr. Zimmermann, Eduardo, “Un espíritu nuevo: la cuestión social y el derecho en la Argentina (1890-1930)", Revista de Indias, 2013.

PROBLEMA

Anuario de Filosofia y Teoría del Derecho, Núm. 8, enero-diciembre de 2014, pp. 147-177 
Esta revista forma parte del acervo de la Biblioteca Jurídica Virtual del Instituto de Investigaciones Jurídicas de la UNAM www.juridicas.unam.mx

http://biblio.juridicas.unam.mx

SOCIABILIDAD Y POLÍTICA EN LA RECEPCIÓN DE UNA TEORÍA

tesis defendida por Duguit "no ha de ser grata al conservatismo". ${ }^{17}$

La crónica periodística señalará en esa ocasión "su aspecto reposado y tranquilo", su "voz agradable" y su hablar pausado, que favorece la comprensión del idioma francés. ${ }^{18}$ Una foto publicada en la revista Caras y Caretas nos muestra a un Duguit hablando concentrado, sentado ante una mesa revestida cubierta de folios esparcidos ante sus ojos. A ambos lados del orador y detrás de él, se encuentran, atentos, sus colegas argentinos. Pero no sólo los oficiales llenan el auditorio: se hallan igualmente presentes los estudiantes de la carrera de derecho, que han conseguido, unos dias antes, la autorización del decano para asistir libremente a las conferencias. Al finalizar su exposición, será aplaudido y rodeado por los concurrentes. El Nacional, diario de la oposición, no se priva de una crónica jocosa, reproduciendo las supuestas opiniones de sus colegas argentinos tras la conferencia de Duguit. ¿Qué visos de verdad puede dársele a la nota? Si fuera el caso, la humorada nos dice posiblemente más de sus supuestos autores (el biologismo de Carlos Octavio Bunge, el tropismo francés de Juan Agustín García, etcétera) que del invitado. Se pueden desprenderse acaso un conjunto de observaciones, por ejemplo, el hecho de que las conferencias son remuneradas generosamente, como ocurrirá (y se le reprochará) a otros visitantes. O aún esa peligrosa cercanía de las ideas de Duguit con la politica: el periodista pone en boca de Alfredo Palacios, notable dirigente del Partido Socialista Argentino, la afirmación: "Nada más que un sindicalista, ninguna novedad", y el antiguo decano Garro asevera que Duguit no será invitado a la conservadora universidad de Córdoba (alusión a un incidente que habría ocurrido durante la visita del socialista Ferri un año antes).

Pareciera que la presencia de catedráticos se va haciendo más escaso con el discurrir de las lecciones: La Vanguardia

17 La Vanguardia, 27 de agosto de 1911.

18 La Nación, 27 de agosto de 1911. 
Esta revista forma parte del acervo de la Biblioteca Jurídica Virtual del Instituto de Investigaciones Jurídicas de la UNAM www.juridicas.unam.mx

http://biblio.juridicas.unam.mx

\section{CARLOS MIGUEL HERRERA}

señala que a partir de la segunda conferencia el público "había disminuido bastante", hasta llegar, en la cuarta, a apenas 6 profesores y una veintena de estudiantes lo que le permite criticar a los universitarios argentinos, "medrosos", "rutinarios", y sobre todo, con "horror a las doctrinas "revolucionarias". ${ }^{19}$ En todo caso, los adjetivos para describirlas son menos entusiastas que los empleados para dar cuenta de las exposiciones del doctor Widal, donde se habla siempre de su "brillante éxito" y se señala que "nunca se había visto una cátedra tan concurrida desde la formación del establecimiento" - una foto nos muestra en todo caso un anfiteatro repleto de la Facultad de Medicina-.

La despedida de Duguit reúne, con todo, "un buen número" de profesores y estudiantes, y no es, por cierto, menos emotiva: Eduardo Díaz de Vivar, presidente del Centro de estudiantes, le agradece en francés sus conferencias, y envía por su intermedio un saludo a los estudiantes de Burdeos. La respuesta de Duguit testimonia sin duda de su agrado, ya que dice considerarse él "también un estudiante, aunque profesor". ${ }^{20} \mathrm{El}$ tono jocoso, una vez más de El Nacional, burlándose del acento correntino y de la pronunciación del estudiante, amén de su larga cabellera, no deja de confirmar el aserto, que lleva al profesor francés a aceptar una visita improvisada a los locales del Centro de estudiantes, junto con otros profesores de la casa de estudios como Estanislao Zeballos o Marco Avellaneda. ${ }^{21}$

Duguit parece concentrado en sus quehaceres universitarios, sin aprovechar su estadia para preparar, contrariamente a Margueritte o antes Clemenceau, una crónica de su viaje para algún diario francés. Nuestro jurista se contentará en dar a la imprenta, pocos meses después del regreso a su patria, el contenido de las conferencias. Los tex-

19 La Vanguardia, 2 y 3 de septiembre de 1911 y 10 de septiembre de 1911.

20 La Prensa 14 de septiembre de 1911.

21 El Nacional 14 de septiembre de 1911, La Nación, 14 de septiembre de 1911 . 
Esta revista forma parte del acervo de la Biblioteca Jurídica Virtual del Instituto de Investigaciones Jurídicas de la UNAM www.juridicas.unam.mx

http://biblio.juridicas.unam.mx

SOCIABILIDAD Y POLÍTICA EN LA RECEPCIÓN DE UNA TEORÍA

tos aparecen en 1912, en francés -de la primera conferencia había sido ya publicada en español en los Anales de la Facultad de Derecho- con el previsible cuidado del autor que asegura que son impresas tal cual fueron pronunciadas, ${ }^{22}$ antes de integrarlas en su opus. ${ }^{23}$ Los textos son publicados en francés pero no sólo en Francia: las conferencias son editadas también en Buenos Aires en el mismo momento en que aparecen en París, y en idioma original -con un título ligeramente modificado: "des transformations", en lugar de "les"-, un hecho nunca antes registrado por bibliografias y biógrafos. ${ }^{24}$ Un año más tarde, y por vias no menos científicas, los textos tendrán una traducción española, aunque esta vez no en la ciudad porteña, sino en Madrid, ampliando aún más la circulación de sus ideas, ya de por sí importante en el contexto francófono de los universitarios de la época.

Por cierto, el viaje a Buenos Aires incluía un vasto programa social, aun para universitarios más o menos austeros. Antes de pronunciar su primera alocución, Duguit visita el edificio de la Universidad de Buenos Aires acompañado por el decano Bidau, que en esos momentos se convierte en su vicerrector, así como la Facultad de Filosofía y Letras. Otro tanto hará el día 22 de agosto con la escuela de derecho donde impartirá sus conferencias, siendo recibido, asimismo, en la redacción de La Nación, que, como recordamos, era una de los principales diarios del país. Recorre incluso la Fa-

22 Se puede dudar en parte de esta afirmación, al menos respecto al aparato de notas, que responde más bien al canon de lo escrito, así como al conjunto de 4 apéndices que se han agregado.

23 Su nuevo estatuto, que lo aleja de toda fragilidad de la oralidad, está sin duda asegurado por la reedición "revue" que hace del texto el autor 10 años después de su primera publicación, con un nuevo prólogo y nuevas notas, aunque sin modificar el texto de las mismas.

24 Son publicadas en los Anales de la Facultad de Derecho, 1912, con excepción de la primera de ellas, que ya había sido dada a conocer en español en la misma revista, un año antes. En París, la primera edición aparece en 1912, impresas por el editor Félix Alcan con el título Les transformations générales du droit privé depuis le code Napoléon. 
Esta revista forma parte del acervo de la Biblioteca Jurídica Virtual del Instituto de Investigaciones Jurídicas de la UNAM www.juridicas.unam.mx

http://biblio.juridicas.unam.mx

\section{CARLOS MIGUEL HERRERA}

cultad de Medicina y el Hospital de Clínicas, que le atrae muy particularmente ya que, como concejal de Burdeos y miembro de la Comisión de hospitales civiles, ${ }^{25}$ se mostraba muy interesado por la organización sanitaria, en particular del hospital de niños (interés que de hecho conservará toda su vida, llegando a ser más tarde miembro del Consejo superior de la Asistencia Pública). Una fotografía publicada en Caras y Caretas registra el hecho, donde se lo ve rodeado por algunos colegas de la Facultad de Derecho, como el ya citado Bidau, Tezano Pintos, J. A. García y Nicanor de Elía. Según la nota, le llama particularmente la atención la maternidad - “c'est épatant", se exclama, según reproduce el periodista- Ya instalado en el ritmo de sus actividades porteñas, el ministro plenipotenciario de Francia, Fouques Duparc, lo presenta al ministro de Relaciones Exteriores, Ernesto Bosch. Entre los banquetes, sobresale el que da en su honor Marco M. Avellaneda, pariente político de Dellepiane, pero sobre todo, director del Departamento Nacional del Trabajo y jurista preocupado por la cuestión social (enseñaba Economía politica en la Facultad de Derecho). Asisten al ágape algunos de los colegas de Duguit en la Facultad de Derecho pero también Joaquín V. González, jurista y universitario respetado, y sobre todo antiguo ministro, e impulsor, como tal, algunos años antes, de un Código de trabajo para la Argentina.

Si el profesor Widal concita la mayor curiosidad de la alta sociedad porteña cuando se sigue la crónica periodística, Duguit quien parece simpatizar con él - lo trae incluso a colación en el cierre de sus conferencias para trazar un paralelo entre la medicina y el derecho, cuyos métodos se basarían cada vez más en la observación de los hechos (fisiológicos en un caso, sociales en el otro)-, coincide con el médico en algunas de esas muestras de interés mundano. Así, Duguit se encuentra con Widal en su visita al Hospital de Clínicas, y comparten el posterior almuerzo en el Jockey Club que se sirve para homenajear al jurista, ocasión en

25 El Diario, 30 de agosto de 1911. 
Esta revista forma parte del acervo de la Biblioteca Jurídica Virtual del Instituto de Investigaciones Jurídicas de la UNAM www.juridicas.unam.mx

http://biblio.juridicas.unam.mx

SOCIABILIDAD Y POLÍTICA EN LA RECEPCIÓN DE UNA TEORÍA

que éste dice estar encantado por la "extraordinaria afabilidad del carácter argentino". Duguit asiste luego a la lección inaugural que su compatriota dicta en la Facultad de Medicina. El médico lo invita a su vez al banquete que da en el lujoso Plaza Hotel para agradecer a sus amistades porteñas, y donde algunas fotografias lo retratan sonriente detrás del organizador del ágape, en el que está presente además Victor Margueritte. Los tres juntos recorren el Hospital Francés, y participan luego de un almuerzo con otros miembros de la colectividad, presidido por el ministro de Francia. Duguit efectúa luego la inevitable visita a los frigoríficos La Negra y La Blanca en compañia de Margueritte, que parece haber estado más interesado que él por las faenas allí desarrolladas, que incluyeron la matanza de algunos animales en homenaje a los huéspedes. Con Widal, nuevamente, realiza la excursión al Castillo de Pacheco Anchorena en el Talar, donde se le muestran los caballos, el ganado, las aves y las perreras, antes de convidarlos con un lunch. Duguit sólo se alejará de la Capital de la República para visitar la ciudad de La Plata, una vez más en compañía del incansable Margueritte, con quien recorrerá la universidad, el puerto, y el por entonces apostadero de Río Santiago. ${ }^{26}$ Su última visita registrada en los diarios es reservada, ya cerca de su partida, al Instituto Nacional Bacteriológico que tenía su sede en los suburbios porteños de Paternal.

El final de su estadía estará envuelto en otras obligaciones protocolares. Tras despedirse personalmente de los ministros argentinos, Duguit partirá para Chile, en lo que presumo es sólo un viaje personal - no encuentro constancias en la literatura de una visita universitaria-, el jueves 14 de septiembre. El Ministerio de Obras Públicas, había decidido reservarle un coche especial en el tren internacional que lo llevaba al país trasandino. Su regreso a Francia se hará

26 Aquí se ve también el carácter austero del universitario, cuando otros visitantes, como Clemenceau o incluso Margueritte visitan distintas ciudades del país. 
Esta revista forma parte del acervo de la Biblioteca Jurídica Virtual del Instituto de Investigaciones Jurídicas de la UNAM www.juridicas.unam.mx

http://biblio.juridicas.unam.mx

CARLOS MIGUEL HERRERA

nuevamente desde el puerto de Buenos Aires, el día 29 del mismo mes.

II

Si la presencia de Duguit en Buenos Aires concitaba un conjunto de rituales repetidos ante los diferentes viajeros europeos, a los que se buscaba impresionar con la pujanza y la modernidad del país, y circula siempre por un sector homogéneo de la sociedad argentina, es en la palabra que puede apreciarse toda la especificidad de su visita.

Las conferencias de Duguit están ordenadas en función de una problemática general, que corresponde a lo que hoy llamariamos un curso universitario. En efecto, asistimos a la exposición de una doctrina del derecho que se ha desarrollado, y ha sido reconocida como tal en la década que precede al viaje. Más aún, hay un núcleo teórico central, que se irá desplegando en sus diferentes lecciones, y que el mismo se encarga de subrayar: el reemplazo de la vieja idea de derecho subjetivo por la nueva noción de "función social".

Pero cabe insistir sobre otro rasgo original de sus conferencias: Duguit no pretende discurrir sólo sobre la realidad europea; entiende, además, avanzar en lo que está ocurriendo en la tierra que lo recibe como huésped por algunas semanas, o al menos sobre su previsible mutación. En efecto, el profesor francés precisa de antemano que las transformaciones jurídicas que estudia son propias igualmente de las sociedades americanas, ya que para él, como lo recalca en la advertencia a la edición de sus textos, la evolución jurídica es la misma en aquellos países que han alcanzado un determinado nivel de desarrollo. Más aún: declara a la prensa que expondrá sus puntos de vista "conforme a la máxima afinidad que pueda existir con la idea argentina", ${ }^{27}$ y aunque más no sea a título ilustrativo, no se priva

27 La Razón, 25 de agosto de 1911. 
Esta revista forma parte del acervo de la Biblioteca Jurídica Virtual del Instituto de Investigaciones Jurídicas de la UNAM www.juridicas.unam.mx

http://biblio.juridicas.unam.mx

SOCIABILIDAD Y POLÍTICA EN LA RECEPCIÓN DE UNA TEORÍA

de citar en sus lecciones a la Constitución de 1853 y, sobre todo, a referirse a diferentes artículos del Código Civil de Vélez Sarsfield -a quién saluda, de hecho, como gran jurisconsulto, dándole a su proyecto una pertinencia práctica pero también teórica- Hará además alguna alusión a ciertos problemas del momento, como la ordenanza que obligaba a cerrar los comercios el día domingo.

$\mathrm{Y}$ el primer elemento que surge de las conferencias de Duguit -ya desde su título- es que el derecho está en un perpetuo estado de transformación. Una mutación independiente de la voluntad del legislador, y que resultaba más bien de la presión de los hechos. La concepción individualista, que se apoyaba en la idea metafisica de derecho subjetivo, está en crisis. Los sistemas jurídicos modernos se asientan en la constatación realista del llamado "hecho de la función social", que se impone tanto a los individuos como a los grupos. ${ }^{28} \mathrm{Si}$ el hombre, visto desde una perspectiva realista, no es titular de "derechos" - que, como lo pretendía la concepción individualista y metafísica, precederían incluso la sociedad-, tiene, en cambio, una función social que cumplir, una cierta tarea que ejecutar, y esta se convierte en el fundamento "socialista" del derecho actual.

Si los profesores porteños habían ya podido escuchar a un antiguo diputado socialista como Ferri disertar sobre la justicia social, no resultaba tampoco habitual en la Facultad de Derecho definir la nueva concepción jurídica como "socialista", como lo hace el jurista francés. Duguit opone el término, con la objetividad del jurista sociólogo que pretende analizar los hechos, a la visión individualista. Sobre todo, y a diferencia de las abstracciones líricas (y pese a su reivindicada condición, de hombre de ciencia) del criminólogo italiano, Duguit entra, con acerada técnica jurídica, en el corazón del problema de la propiedad individual. Se trata, como él mismo se encarga de detallarlo, de un derecho cuyo fundamento reside en las condiciones propias de la vida DE

28 Duguit, op. cit., pp. 4-9. 
Esta revista forma parte del acervo de la Biblioteca Jurídica Virtual del Instituto de Investigaciones Jurídicas de la UNAM www.juridicas.unam.mx

http://biblio.juridicas.unam.mx

\section{CARLOS MIGUEL HERRERA}

social, en la estructura social, algo que venía afirmando en su obra. ${ }^{29}$

Duguit ponía la noción de función social en relación con el concepto durkheiminiano de solidaridad social, o como prefiere decir, para alejarse de toda contaminación politica, de "interdependencia social", y que constituye un hecho, el hecho mismo de la estructura social. En particular, esa solidaridad por división del trabajo que es propia de las sociedades modernas civilizadas, uniendo a los hombres a través de una diferencia de situaciones y aptitudes que los lleva a colaborar mutualmente para dar satisfacción a esas necesidades diversas. ${ }^{30}$ Es sobre ella que reposa el derecho, ya que todo individuo, por el sólo hecho de vivir en sociedad, está obligado a cumplir una función, que tiene su propio valor social y debe ser como tal protegida. ${ }^{31}$ Si Duguit venía sosteniendo estas tesis desde hacía más de una década, en las conferencias porteñas estudiará las transformaciones que esta nueva concepción implicaba en el derecho privado, a través de las nociones de libertad, contrato, propiedad y responsabilidad.

Pero las consecuencias politicas de su posicionamiento teórico son evidentes y el propio conferencista se encarga de detallarlas. En nombre de la libertad-función, Duguit se declara favorable a la limitación de la jornada de trabajo, al descanso semanal y a la jubilación obligatoria, sancionadas

29 Duguit, Léon, Les transformations du droit privé depuis le Code Napoléon (1912), París, Alcan, 1920, p. 25. Aunque nuestro jurista aclare enseguida que el uso del término no suponga adhesión alguna al programa del partido socialista, llama la atención, sin embargo, ya avanzado el siglo $\mathrm{XX}$, y luego de que se haya desarrollado incluso una corriente de "socialismo jurídico" con la que Duguit ha tomado explícita distancia, que recurra a dicho término, que, cuanto menos, podía dar lugar a malos entendidos, mucho más en un país como la Argentina.

30 Para una presentación sintética de sus ideas, véase Herrera, Carlos Miguel, "La teoría del derecho de Léon Duguit", en vários autores, Ensayos de derecho público en conmemoración del sesquicentenario del natalicio de León Duguit, Monterrey, Lazcano Garza, 2011.

31 Duguit, cit., p. 29. 
Esta revista forma parte del acervo de la Biblioteca Jurídica Virtual del Instituto de Investigaciones Jurídicas de la UNAM www.juridicas.unam.mx

http://biblio.juridicas.unam.mx

SOCIABILIDAD Y POLÍTICA EN LA RECEPCIÓN DE UNA TEORÍA

por ley. Por cierto, tras haber rechazado el principio de la libertad contractual hace lo propio con la idea de lucha de clases, ya que se trata de proteger el valor social del trabajo, representado por el individuo, y no únicamente al obrero contra el empleador. ${ }^{32}$ Empero, en nombre del fin de la ficción de la personalidad, Duguit resaltaba el número importante de asociaciones obreras, profesionales, económicas, artísticas, científicas que son titulares de derechos en Francia, y que ha llevado a terminar con la vieja ley Le Chapelier, reconociendo a las asociaciones obreras, y luego a la libertad de asociación. En efecto, el centro neurálgico de las sociedades modernas no se encontraba tan solo en los grupos sociales: pasa sobre todo por las agrupaciones profesionales, es decir las clases sociales organizadas en sindicatos. ${ }^{33}$ Tras señalar una diferencia importante con la sociedad argentina, ya que la vida asociativa era aún incipiente en estos lares, Duguit afirmaba que la protección jurídica de la actividad colectiva no podía depender de la arbitrariedad gubernamental allí donde se estaba ante un asociacionismo activo. ${ }^{34}$

Ese fin de solidaridad social marcaba asimismo la doctrina de los contratos, en particular gracias a la obra de la jurisprudencia, lo que a su vez lo llevaba a pensar que el acto discrecional en derecho administrativo estaba también desapareciendo. Nuevas realidades jurídicas aparecen pues a través de este proceso objetivo, como los llamados contratos colectivos, en particular la concesión de servicios públicos y la convención colectiva de trabajo, que eran, en realidad, actos que regulaban situaciones. En todo caso, dicho contrato colectivo de trabajo, que la Argentina no conocía todavía (como el mismo Duguit se encarga de subrayar), era una categoría nueva que no podía ser entendida con las tradicionales nociones civilistas: se trataba de una ley que establece un régimen legal permanente y duradero entre

32 Ibidem, pp. 44-50.

33 Ibidem, p. 74.

34 Ibidem, p. 64. 
Esta revista forma parte del acervo de la Biblioteca Jurídica Virtual del Instituto de Investigaciones Jurídicas de la UNAM www.juridicas.unam.mx

http://biblio.juridicas.unam.mx

\section{CARLOS MIGUEL HERRERA}

dos grupos sociales, regulando los contratos individuales entre los miembros de ambos grupos - la ley de un Estado sin soberanía en el sentido tradicional del término, como lo señalaba de manera expresiva en su exposición-. Finalmente, en la llamada "responsabilidad objetiva", que nacía de los hechos, y en particular del riesgo, veía Duguit otra consecuencia de la socialización del derecho. En especial, en el caso de los accidentes de trabajo, cuya organización por ley constituía para él una de las pruebas más fehacientes de la ruina del individualismo.

No había tardado mucho Duguit en anunciar en sus lecciones la desaparición de las concepciones jurídicas establecidas por el Código Napoleón (y la Declaración de 1789). Pero dejará para el final, modificando en parte el orden que había informado en la prensa, la propiedad privada, capitalista. Para el jurista francés, como toda institución jurídica, ésta obedecía a necesidades económicas, y por ende la categoría se transformaba con ellas. ${ }^{35}$ No sólo dejaba de ser un derecho individual para transformarse en una función social: además, las formas colectivas se volvían cada vez más abundantes aunque advierte, una vez más, que se trata de una realidad en ciernes en América del Sur, en particular en materia de tierras. Pero puesto que la propiedad consiste en afectar un conjunto de riquezas a un fin, nada impediría que ésta se organizase en función de fines sociales. En verdad, el individuo no es más que un medio, ya no un fin; la propiedad se transforma en un instrumento para mantener y acrecentar la interdependencia social, y por ende, en un deber para el propietario. Sólo debía ser protegida en la medida en que cumplía su función social, aquella de aumentar el bienestar material, la riqueza general de la comunidad. La observación de los hechos probaba según el conferencista que el dominio era una noción metafísica, y el derecho sólo podía garantizar al propietario la libertad para cumplir su fin social.

35 Ibidem, p. 148. 
Esta revista forma parte del acervo de la Biblioteca Jurídica Virtual del Instituto de Investigaciones Jurídicas de la UNAM www.juridicas.unam.mx

http://biblio.juridicas.unam.mx

SOCIABILIDAD Y POLÍTICA EN LA RECEPCIÓN DE UNA TEORÍA

Por si fuera necesario, Duguit aclarará a su público que no estaba sosteniendo que la propiedad privada debía desaparecer; más bien que la noción jurídica se había transformado, asegurando a sus interlocutores que la propiedad se encontrará así mejor protegida que con la concepción tradicional. Incluso, no se priva de recordar que la propiedad era la base de la prosperidad y asegura que las doctrinas colectivas son un regreso a la barbarie. Es más: no duda en sostener que es un "crimen" predicar la lucha de clases, promoviendo en cambio la concepción sindicalista de la organización y jerarquización de las clases sociales que defiende en esos años. ${ }^{36}$ Aunque la cuestión no sea directamente evocada por Duguit en sus conferencias porteñas, este se oponía de manera vigorosa a la huelga, una idea que estaba muy presente entre muchos de sus interlocutores argentinos de 1911.37

Empero, la propiedad tiene una función social, y cuando el propietario no la realizaba, los gobernantes estaban legitimados para intervenir, para obligarlo a cumplir con ella. Duguit no temía salir de su reserva por una vez y aseguraba que la Argentina, que se encuentra aún en un estadio de propiedad-especulación, evolucionará rápidamente hacia la propiedad-función, haciendo desaparecer la idea de "propiedad-derecho". Sugiere incluso que la pura especulación de la tierra, es decir sin ninguna explotación, debía ser prohibida de manera legitima, mostrando una vez más que la propiedad no era ya más un derecho intangible. ${ }^{38}$ Por cierto, el cronista socialista de La Vanguardia lo acusará de silenciar otros hechos aún más "ostensibles y universales" y, sobre todo, de contradecirse en su negación de la "moderna" lucha de clases, lo que lo lleva a calificar, desilusionado, su última conferencia de "mediocre".

36 Ibidem, p. 21, y pp. 160-161.

37 Por ejemplo, M. Avellaneda recurría a la misma imagen de la guerra, por otro lado corriente, que el jurista bordelés (citado en Zimmermann, Eduardo, Los liberales reformistas, Buenos Aires, Sudamericana, 1995, p. 89).

38 Ibidem, pp. 150 y 164. 
Esta revista forma parte del acervo de la Biblioteca Jurídica Virtual del Instituto de Investigaciones Jurídicas de la UNAM www.juridicas.unam.mx

http://biblio.juridicas.unam.mx

CARLOS MIGUEL HERRERA

III

Conviene distinguir entre las repercusiones que las conferencias de Duguit pudieron tener en lo inmediato con la recepción de sus ideas. Con respecto a la primera dimensión, todo parece indicar que aquellas fueron más bien negativas, o al menos poco entusiastas. En ella se alternan sin duda cierta incomodidad por la osadía de algunas tesis que tocan a la propiedad privada (en particular de la tierra), y el carácter demasiado, abiertamente político de sus proposiciones jurídicas, aunque no presenten más que un sentido finalmente conservador. En el fondo, es menos el contenido de las posiciones en sí que el tipo de relación que instauraría entre el derecho y la política (no es casual que se lo tache de "sociólogo", incluso entre los civilistas argentinos más receptivos a su posición).

La recepción florecerá, por cierto, de manera más lenta. De manera global, se puede avanzar el juicio que será, finalmente, menos importante en Argentina que en otros países de América del Sur, como Brasil o Colombia, donde son, a su vez, más tardías. Pero, de manera quizás paradójica, la primera recepción jurídica en Argentina sigue une vía particular que, aun teniendo poco que ver con el fondo del pensamiento de nuestro jurista, acepta el tipo de relación estructural que establece entre política y derecho. Si, en efecto, la recepción de las ideas de Duguit en América latina seguirá al menos tres vías, una vía antiformalista, una vía corporativa y una vía socialista, es esta última que, en Argentina, parece ser la primera en expresarse en el ámbito de la ciencia jurídica, aunque más no sea en sus márgenes disciplinarios, sobre todo, en el campo de la filosofia del derecho.

Cabe subrayar también que Duguit presentaba sus ideas en un contexto particular de la Argentina, donde una parte de las élites comenzaban a pensar cada vez que "el proble- 
Esta revista forma parte del acervo de la Biblioteca Jurídica Virtual del Instituto de Investigaciones Jurídicas de la UNAM www.juridicas.unam.mx

http://biblio.juridicas.unam.mx

SOCIABILIDAD Y POLÍTICA EN LA RECEPCIÓN DE UNA TEORÍA

ma político es sociológico". ${ }^{39}$ No por casualidad, en ese mismo año de 1911 se creaba el Museo social argentino, una institución que buscaba reunir a los principales especialistas argentinos, juristas en su mayoría (entre los que se contaban no pocos de los interlocutores del profesor bordelés durante su visita), de la cuestión social, incluyendo también a algunos caracterizados miembros del Partido Socialista, con el fin de facilitar las investigaciones y la documentación en torno al problema, pero promoviendo también cierto tipo de soluciones (cooperativismo, mutualismo, etcétera). En las páginas que dedicaba a su reciente experiencia por América, Adolfo Posada remarcaba la existencia de un ambiente general en favor del intervencionismo que venía de "la activa propaganda socialista [...] y de la acción del influjo de las gentes intelectuales que se interesan de alguna manera por los problemas sociales". 40

La cuestión social permeaba entre los juristas de la Facultad de Derecho. En 1909, A. Dellepiane aseveraba a los abogados recién egresados: "démonos prisa, sobre todo, en

39 Afirmación de Carlos Ibarguren, en la colación de grados de agosto de 1912 (la cambiará en sus memorias por "social”). Las posiciones políticas de Duguit son sin duda más cercanas a las de otro visitante de la Argentina del Centenario, G. Clemenceau, para quien el Estado realiza su "deber", un tema caro al jurista bordelés, dictando leyes de bienestar social, aunque juzga que esa legislación no debe atentar contra la libertad individual. Para Clemenceau la democracia estaba "intimamente ligada" a la cuestión social. Y aunque atacaba la CGT y los sindicatos por fomentar la revolución y la lucha de clases, sostiene que sólo la democracia es capaz de construir una ciudadanía en la que todos sus miembros se reconcilien en un "esfuerzo común de solidaridad".

40 Posada, Adolfo, En América: una campaña, Madrid, Beltrán, 1911. Es sintomático que poco después, al describir la República Argentina, donde acaba de pasar medio año, Posada trate en el mismo capítulo al Partido Socialista y al Departamento Nacional del Trabajo (la repartición ministerial que se ocupaba de las cuestiones ligadas a los trabajadores), bajo el título "el socialismo argentino, los obreros y la reforma social" (Posada, Adolfo, La República Argentina (1912), Hyspamérica, 1986. Este espacio de confluencia entre las élites reformistas liberales y el socialismo parlamentario es descripto en Zimmermann, Los liberales reformistas, idem. 
Esta revista forma parte del acervo de la Biblioteca Jurídica Virtual del Instituto de Investigaciones Jurídicas de la UNAM www.juridicas.unam.mx

http://biblio.juridicas.unam.mx

CARLOS MIGUEL HERRERA

la exploración de las cuestiones sociales, porque la solución, en este caso, es más urgente que en otro alguno". Con todo, el tono era de conciliación y no sólo de parte de los catedráticos argentinos; al dedicar, un año antes de la venida de Duguit, su primera conferencia en la Facultad de Derecho a "La Justicia social", el socialista Ferri, la situaba en un plano de coincidencia de intereses, del obrero y el capitalista, de la Argentina y la inmigración. Cuando Dellepiane, presentando estas conferencias, hablaba a su vez de solidaridad, era para asociarla de hecho a la concordia social, a la pacificación. No por nada el periódico socialista $L a$ Vanguardia criticaba a Duguit por ignorar —aunque en realidad le reprocha más bien silenciar su doctrina ante una conservadora Facultad de derecho- que la moderna lucha de clases conducía a una armonía, y no se la podía contraponer a la interdependencia, como aquel lo pretendia.

Ciertamente, la recepción que la doctrina jurídica podía hacer de las ideas sociales en su dominio propio iba a ser particularmente lenta. ${ }^{41}$ En verdad, la idea de solidaridad

41 Diez años después de la visita de Duguit, en momentos en que se festeja el cincuentenario del Código civil argentino, A. Colmo podía exclamarse: "para nuestros jueces, el derecho romano, Pothier o Laurent (y no menciono ciertos autorcillos...), son un evangelio; Saleilles y Gény, o la Corte de casación no son nadie..." (Colmo, Alfredo, El Código Civil en su cincuentenario, Buenos Aires, Rosso, 1921, p. 22). Colmo ilustra una primera (y moderada) recepción antiformalista de Duguit, sobre todo cuando afirma que los derechos deben ser una función más que una potestad, Idem., pero tal vez la referencia al jurista bordelés es menos exclusiva de lo que se ha sostenido. De manera general, Colmo sostenía que "el derecho antropomórfico e individualista tiene que ceder lugar al derecho objetivo, social y solidario, congruente con las modernas condiciones de vida" (Colmo, Alfredo, Politica cultural en los paises latinoamericanos, Buenos Aires, Nosotros, 1925, p. 20). Pero tomaba explícitas distancias de la concepción de Duguit, poniendo en cuestión su originalidad en la visión del derecho como fenómeno social, y, sobre todo, distancia con las consecuencias de esta visión, que dice rechazar, Ibidem, p. 142. En verdad, Colmo ubica en el centro de su visión a Saleilles, "la más alta expresión del civilismo francés", subrayando "las finuras de su talento perspicaz y 
Esta revista forma parte del acervo de la Biblioteca Jurídica Virtual del Instituto de Investigaciones Jurídicas de la UNAM www.juridicas.unam.mx

http://biblio.juridicas.unam.mx

SOCIABILIDAD Y POLÍTICA EN LA RECEPCIÓN DE UNA TEORÍA

no era ajena a los juristas argentinos, al menos a los más avanzados: Alfredo Colmo, profesor de derecho civil, en la conferencia inaugural a su curso del año 1909 no sólo se muestra atento a lo que llama los "criterios sociológicos" sino que señala que "la característica saliente de la vida moderna es la solidaridad, la socialidad". ${ }^{42}$

Pero, de manera general, la ciencia jurídica se mostraba muy reacia a tomar contacto con lo político y el propio Duguit, a lo largo de su obra, estará siempre atento a alejar su concepción "jurídica" del fundador del solidarismo, Léon Bourgeois, e inclusive en sus conferencias porteñas hará una referencia crítica a esos políticos que se han querido apropiar del concepto de solidaridad, trastocando su sentido. Sin embargo, el engarce entre pensamiento social y teoría jurídica podía realizarse más rápidamente en un lugar particular, aquel que veía desarrollar una visión socialista de derecho. ${ }^{43}$

Alfredo L. Palacios, el primer diputado socialista electo en un parlamento de América, expresaba de manera transparente esta convergencia. En momentos mismos en que se desarrollaba la visita de Duguit, Palacios, que asiste a sus conferencias, estaba dictando por primera vez su curso de "Filosofia del derecho", para el que había sido designado

hondo". (Colmo, Alfredo, "El nuevo programa de derecho civil", Anales de la Facultad de Derecho y Ciencias Sociales, 1912, t. II). Juzga en cambio a Duguit como un sociólogo, o un filósofo, interesado por el derecho en general.

42 Colmo, Alfredo, Carácter del derecho civil contemporáneo, Buenos Aires (Separata de la Revista de la Facultad de Derecho y Ciencias Sociales), p. 11. "Socialidad" que también él separa del socialismo. Por cierto, Colmo, gran conocedor de la literatura jurídica francesa de la época, no cita a Duguit, refiriéndose a Gény, Esmein y sobre todo a Saleilles. En su libro de 1905, Principios sociológicos, Colmo había ya mostrado sus conocimientos de la sociologia, sobre todo de Durkheim, una vez más sin pasar por Duguit. Por último, no encuentro registro periodístico que Colmo hubiera seguido las conferencias de Duguit en 1911.

43 Cfr. Herrera, Carlos Miguel, Derecho y socialismo en el pensamiento jurídico, Bogotá, Universidad Externado de Colombia, 2002. 
Esta revista forma parte del acervo de la Biblioteca Jurídica Virtual del Instituto de Investigaciones Jurídicas de la UNAM www.juridicas.unam.mx

http://biblio.juridicas.unam.mx

\section{CARLOS MIGUEL HERRERA}

como profesor suplente a fines de 1910, provocando con ello, dicho sea de paso, la renuncia de algunos catedráticos de la Facultad. Quizás ya familiarizado con los escritos de Duguit, o, más probablemente, con otros pensadores que le son una común referencia, como Auguste Comte, Palacios negaba la validez de un método a priori, sosteniendo que los hechos debían ser estudiados de manera empírica y por inducción. Y los fenómenos jurídicos son hechos sociales. Por ende, el derecho "no puede ser absoluto, ni inmutable, ni eterno" y hay que desembarazarse de las investigaciones metafísicas. ${ }^{44}$ Aunque no hay entonces referencias directas a Duguit, la convergencia se torna explícita en 1919, cuando Palacios pronuncie una serie de conferencias sobre "Legislación de trabajo" que serán publicadas al año siguiente bajo el título El Nuevo derecho. En sus páginas, Palacios se permite incluso entrelazar los nombres del jurista francés y el de Jean Jaurès que, como sabemos, había visitado la Argentina en el mismo año de $1911 .{ }^{45}$

Palacios recuerda alli que para Duguit la concepción individualista del derecho desaparecerá ante el hecho de la función social, para dar lugar a un sistema socialista. Aunque retiene el peculiar sentido dado a la palabra por el jurista francés, utiliza el argumento para cuestionar las posiciones del por entonces decano de la Facultad de Derecho, Estanislao Zeballos, que ponía todavía en duda la necesidad de una legislación social en la Argentina. Y aludiendo a las ideas de Jaurès en los Etudes socialistes, sobre los que se apoya ampliamente, expone la tesis de un germen socialista en el derecho civil burgués, que se expresaba ya por el estatuto de la propiedad privada, y permitía la emergencia de la propiedad colectiva. ${ }^{46}$

44 Palacios, Alfredo, "El método de la filosofia del derecho", Anales de la Facultad de Derecho y Ciencias Sociales, 1911, t. I, pp. 514-515.

45 Sobre la visita del tribuno francés a Buenos Aires, véase Herrera, "Jaurès en la Argentina...", cit.

46 Palacios, Alfredo, El nuevo derecho (Legislación del trabajo), Lajouane, 1920. Palacios considera a Jaurès como la figura más vigorosa de la 
Esta revista forma parte del acervo de la Biblioteca Jurídica Virtual del Instituto de Investigaciones Jurídicas de la UNAM www.juridicas.unam.mx

http://biblio.juridicas.unam.mx

SOCIABILIDAD Y POLÍTICA EN LA RECEPCIÓN DE UNA TEORÍA

El lugar de Duguit en la reconstrucción de una visión socialista del derecho no dejará de aumentar, sobre todo con el cambio de contexto en la recepción de sus ideas que se produce a finales de los años 1920 y durante la década siguiente, e incluso entre autores que no son siquiera juristas profesionales. Un constitucionalista socialista, Carlos Sánchez Viamonte, no dudará por entonces en calificar a Duguit como "como el más formidable destructor del derecho liberal en materia económica". ${ }^{47}$ Que Duguit termine su obra afirmando que "el único medio de combatir al comunismo es enseñar que la propiedad capitalista no es un derecho sino una función"48 no desautorizaba este tipo de apropiaciones. En todo caso no eran propias de interpretaciones erróneas de una lejana y descentrada Argentina: el jurista alemán Gustav Radbruch daba a Duguit, en esos mismos años 1920, un lugar central en la reconstrucción de una visión social del derecho y la propia prensa francesa lo caracterizaba en esos mismos momentos como un constitucionalista de izquierdas.

Pero el contexto inmediato en que Duguit había desarrollado sus lecciones estaba marcado por el cambio. Un año antes, Georges Clemenceau le advertía al público burgués que asistía a sus conferencias: "se equivocan si se creen ajenos al problema social", reivindicando en esa ocasión la importancia de legislación social, "obra de justicia" que no era incompatible con la libertad individual. ${ }^{49}$ Previsiblemente, el nuevo clima se expandía más rápidamente en el cam-

democracia moderna. Sobre las ideas jurídicas del político francés, véase Herrera, Derecho y socialismo ..., cit.

47 Cfr. Herrera, Carlos Miguel, "Socialismo jurídico y reformismo politico en Carlos Sánchez Viamonte", Revista de Estudios Políticos, núm. 113, 2001. Tanto en el ámbito de la Facultad de Derecho como en el jurídico-político se puede pensar sin embargo que la recepción de Duguit pasa más por su crítica al código civil que por la aceptación de sus principios metodológicos e incluso su visión solidarista.

48 Duguit, Léon, El pragmatismojurídico, Madrid, Beltrán, 1924, p. 111.

49 Clemenceau, Georges, Sur la démocratie, Paris, Larousse, 1930, pp. 98-115. 
Esta revista forma parte del acervo de la Biblioteca Jurídica Virtual del Instituto de Investigaciones Jurídicas de la UNAM www.juridicas.unam.mx

http://biblio.juridicas.unam.mx

CARLOS MIGUEL HERRERA

po político que en el doctrinal: el gobierno del presidente Roque Saénz Peña, electo en 1910, no tardaría en presentar un ambicioso proyecto de ley de socorros mutuos ante las Cámaras, cuyo mensaje concluía: "la democracia argentina, impulsada por este gobierno en el orden politico, se ha de encauzar, desde el punto de vista social, en el mutualismo, que significa no sólo asistencia, previsión y ahorro, sino también unión nacional y fraternidad humana". ${ }^{50} \mathrm{E} 1$ regreso de Alfredo Palacios, esta vez acompañado de Juan B. Justo, a la Cámara, como representantes del Partido Socialista tras las elecciones libres de abril de 1912, se contaba entre los efectos más inmediatos de un cambio de época, al menos en el plano político.

La palabra de un "sindicalista" como Duguit en la vieja y conservadora Facultad de derecho parecía estar más en diapasón con la conciencia de la necesidad de una evolución en las relaciones sociales que comenzaba a expandirse entre la élite gobernante argentina que con los especialistas de derecho civil argentino. En todo caso, la argumentación de Duguit anunciaba ya a la doctrina jurídica que una nueva concepción del derecho era necesaria para pensar las transformaciones sociales.

50 Otros visitantes franceses, como Léopold Mabilleau (1859-1941), gran figura de mutualismo, con un perfil más técnico que el de profesor o tribuno, pero particularmente activo, parecen haber jugado un papel importante de asesoramiento en los círculos gubernamentales. Director del Musée social francés, que servía de modelo a su homólogo argentino, visitará al país dos ocasiones, en 1912 y 1913. Cfr. Ibarguren, Carlos, La historia que he vivido, Buenos Aires, Peuser 1955, p. 253. Para la propia posición de Ibarguren en el ámbito de las ideas sociales, véase Herrera, Carlos Miguel, "En los orígenes del constitucionalismo social argentino - Discursos en torno a la Constitución de 1949" (2009), en P. González Bernaldo, R. González Leandri (eds.), Actores, prácticas e instituciones en la construcción de políticas sociales en las Américas, Madrid, GEA (en prensa). Estimo importante, aunque más no sea analíticamente, separar el campo de la doctrina jurídica del de los reformadores sociales.

PROBLEMA

Anuario de Filosofia y Teoría del Derecho, Núm. 8, enero-diciembre de 2014, pp. 147-177 
Esta revista forma parte del acervo de la Biblioteca Jurídica Virtual del Instituto de Investigaciones Jurídicas de la UNAM www.juridicas.unam.mx

http://biblio.juridicas.unam.mx

SOCIABILIDAD Y POLÍTICA EN LA RECEPCIÓN DE UNA TEORÍA

BIBLIOGRAFÍA

Periódicos

Caras y Caretas

El Diario

El Nacional

La Prensa

La Nación

La Razón

La Vanguardia

BIDAU, Eduardo L., "Palabras pronunciadas por el decano de la Facultad, doctor Eduardo L. Bidau, al presentar al profesor Duguit", Anales de la Facultad de Derecho y Ciencias Sociales, t. I, 1911.

Colmo, Alfredo, Carácter del derecho civil contemporáneo, Buenos Aires (separata de la Revista de la Facultad de Derecho y Ciencias Sociales), 1909.

Colmo, Alfredo, "El nuevo programa de derecho civil", Anales de la Facultad de Derecho y Ciencias Sociales, t. II, 1912.

Colmo, Alfredo, El Código Civil en su cincuentenario, Buenos Aires, Rosso, 1921.

Colmo, Alfredo, Politica cultural en los paises latinoamericanos, Buenos Aires, Nosotros, 1925.

Dellepiane, Antonio, “Colación de grados" (1909), Discursos académicos, Buenos Aires, Facultad de Derecho, t. I, 1911.

DuGUiT, Léon, "Conferencia del profesor Duguit", Anales de la Facultad de Derecho y Ciencias Sociales, t. I, 1911. 
Esta revista forma parte del acervo de la Biblioteca Jurídica Virtual del Instituto de Investigaciones Jurídicas de la UNAM www.juridicas.unam.mx

http://biblio.juridicas.unam.mx

\section{CARLOS MIGUEL HERRERA}

DUGUIT, Léon, Les transformations du droit privé depuis le Code Napoléon (1912), París, F. Alcan, 1920.

Duguit, Léon, El pragmatismo jurídico, Madrid, Beltrán, 1924.

Clemenceau, Georges, Sur la démocratie (neuf conférences rapportées par M. Ségard), París, Larousse, 1930.

IBARGUREn, Carlos, La historia que he vivido, Buenos Aires, Peuser, 1955.

PALACIOS, Alfredo L., "El método de la filosofia del derecho", Anales de la Facultad de Derecho y Ciencias Sociales, t. I, 1911.

Palacios, Alfredo L., El nuevo derecho (legislación del trabajo), Buenos Aires, Lajouane, 1920.

PosAdA, Adolfo, En América: una campaña, Madrid, Beltrán, 1911.

PosadA, Adolfo, La República Argentina (1912), Buenos Aires, Hyspamérica, 1986.

\section{Literatura secundaria}

DELPY, Gaspard, "Ernest Martinenche”, Bulletin Hispanique, 1942.

HERRERA, Carlos Miguel, "Jean Jaurès et l'idée de droit social”, Cahiers Jean Jaurès, núm. 156, 2000.

HERRERA, Carlos Miguel, "Socialismo jurídico y reformismo político en Carlos Sánchez Viamonte", Revista de Estudios Politicos, Madrid, núm. 113, 2001.

HERrera, Carlos Miguel, Derecho y socialismo en el pensamiento jurídico (trad. de V. Lozano y C. Bernal Pulido), Bogotá, Universidad Externado de Colombia, 2002.

HERRERA, Carlos Miguel, "Jaurès en la Argentina - La Argentina de Jaurès”, Estudios Sociales, núm. 37, 2009. 
Esta revista forma parte del acervo de la Biblioteca Jurídica Virtual del Instituto de Investigaciones Jurídicas de la UNAM www.juridicas.unam.mx

http://biblio.juridicas.unam.mx

SOCIABILIDAD Y POLÍTICA EN LA RECEPCIÓN DE UNA TEORÍA

HERRERA, Carlos Miguel, "En los orígenes del constitucionalismo social argentino - Discursos en torno a la Constitución de 1949" (2010), en GONZÁlEZ BERNALDO, P. y GONZÁLEZ LEANDRI, R. (eds.), Actores, prácticas e instituciones en la construcción de politicas sociales en las Américas, Madrid, GEA (en prensa).

HERRERA, Carlos Miguel, "La teoría del derecho de Léon Duguit", en vários autores, Ensayos de derecho público en conmemoración del sesquicentenario del natalicio de León Duguit, Monterrey, Lazcano Garza, 2011.

HERRERA, Carlos Miguel, "Renovación y crítica del derecho en Francia durante la Tercera República", en GARCÍA VILLEGAS, Mauricio y SAFFON, María Paula (eds.), Critica jurídica comparada, Bogotá, Universidad Nacional de Colombia, 2011.

LÓPEZ MEDINA, Diego, Teoría impura del derecho. La transformación de la cultura jurídica latinoamericana, Bogotá, 2004.

SARLO, Oscar, "La gira suramericana de Hans Kelsen en 1949: el "frente del sur" de la teoría pura", en RAMÍREZ Cleves, Gonzalo (ed.), Ecos de Kelsen, Bogota, Universidad Externado de Colombia, 2013.

ZIMMERMANN, Eduardo, Los liberales reformistas, Buenos Aires, Sudamericana, 1995.

ZIMMERMANN, Eduardo, "Un espíritu nuevo": la cuestión social y el derecho en la Argentina (1890-1930)", Revista de Indias, 2013. 